\title{
Wernicke's Encephalopathy
}

\author{
Smit Patel ${ }^{1}$, Karan Topiwala $^{1}$, Lawrence Hudson ${ }^{1}$ \\ 1. Neurology, Hartford Hospital, Hartford, USA
}

Corresponding author: Smit Patel, drsmitpatel1988@gmail.com

\begin{abstract}
Wernicke's encephalopathy (WE) is a neurologic emergency that requires immediate attention to prevent permanent neurological morbidity and mortality. It presents with confusion, ophthalmoplegia and gait ataxia which together comprise its classic triad. Thiamine deficiency related to alcohol abuse remains the primary culprit; non-alcoholic WE, however, can have an atypical clinical presentation and is often missed. Thus, although the diagnosis of WE remains primarily clinical, neuroimaging plays an important role, especially in the diagnosis of non-alcoholic WE. Here, we present a case of non-alcoholic WE with an atypical clinical presentation but typical magnetic resonance imaging (MRI) findings in a woman with a history of non-bariatric gastrointestinal surgery. Thiamine replacement therapy rapidly reversed her neurologic symptoms and MRI findings.
\end{abstract}

Categories: Medical Education, Neurology, Preventive Medicine

Keywords: wernicke's encephalopathy, thiamine, alcohol toxicity, delirium, sun downing, vitamin b1, 5 fu infusion, stroke prevention

\section{Introduction}

In 1881, Carl Wernicke described acute encephalopathy as characterized by mental confusion, ophthalmoplegia, nystagmus and gait ataxia. A few years later, a Russian psychiatrist named Sergei Korsakoff extended this syndrome by including memory loss and confabulation as the subsequent neuropsychiatric manifestations of the illness now known as Wernicke-Korsakoff syndrome (WKS) [1]. Wernicke encephalopathy (WE) is an acute neurological emergency resulting from a deficiency of thiamine (vitamin B1), the most common cause of which is alcohol abuse; however, prolonged starvation, hyperemesis gravidarum and gastrointestinal surgery can also lead to WE [2]. The prevalence of WE in the general population is about $0.4 \%$ to $2.8 \%$ but can be as high as $12.5 \%$ in alcohol abusers and up to $59 \%$ in alcoholrelated deaths [2-3]. A pathological examination of acute lesions demonstrates vascular congestion with or without petechial haemorrhages, while chronic lesions can be demyelinating and gliotic with atrophy of the mammillary bodies being highly specific to WKS [4]. WE remains a clinical diagnosis which can be made even with normal blood thiamine levels and with magnetic resonance imaging (MRI) having a sensitivity and specificity of $53 \%$ and $93 \%$, respectively [5]. The diagnosis of non-alcoholic WE seems trickier due to its atypical course. We herein described a non-alcoholic woman with an atypical clinical presentation but typical MRI findings [6-7].

Received 07/24/2018

Review began 07/31/2018

Review ended 08/16/2018

Published 08/22/2018

๑) Copyright 2018

Patel et al. This is an open access article distributed under the terms of the Creative Commons Attribution License CC-BY 3.0., which permits unrestricted use, distribution, and reproduction in any medium, provided the original author and source are credited.

\section{Case Presentation}

A 63-year-old woman, with a history of Boerhaave's oesophageal rupture status post-oesophagectomy with extra-thoracic transverse colon interposition 40 years ago, presented with two weeks of malaise and was found to have a non-mechanical primary bowel dysmotility. She was dehydrated and resuscitated in the emergency room with intravenous (IV) normal saline which was later switched to IV 5\% dextrose normal saline. Over the next week, she became progressively more lethargic and was thought to be delirious with “sundowning”. On neurologic examination, she was drowsy but arousable to verbal stimuli with bilateral vertical and horizontal ophthalmoplegia. An MRI of the brain showed symmetrical hyperintensity in the bilateral medial thalami and dorsal midbrain, including periaqueductal grey matter, as shown in Figure 1 . She was started on high-dose IV thiamine (500 mg three times daily for two days followed by $250 \mathrm{mg}$ daily for five days followed by oral treatment with $100 \mathrm{mg}$ daily) along with other B-complex vitamins and magnesium. Repeat brain MRI one week later showed significantly reduced hyperintensities in the thalamus and the dorsal midbrain region. Unfortunately, her hospital course was complicated by Pseudomonas and Klebsiella pneumonia requiring intubation, along with sepsis and progressive multiple organ failure. She passed away after the goal of her care was changed to comfort measures only. 


\section{Cureus}

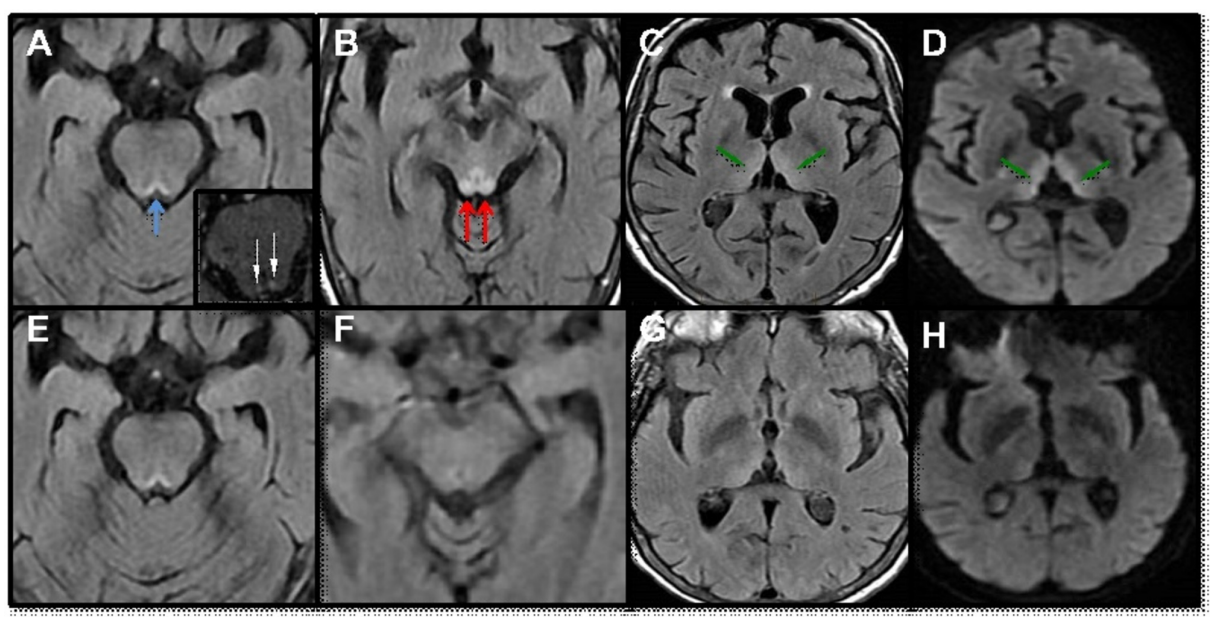

\section{FIGURE 1: Changes on MRI with Wernicke's encephalopathy}

MRI brain with contrast showing T2 FLAIR signal hyperintensity involving the inferior tectal plate (A, blue arrow) with enhancement (A, inset) as well as the periaqueductal gray matter within the dorsal midbrain (B, red arrow). There is also involvement of the the medial thalami bilaterally (green arrow) on T2 FLAIR (C) as well as on DWI (D). Patient was treated with high dose intravenous thiamine with repeat MRI brain, one week later showing a significant improvement $(E, F, G$ and $H)$

MRI: magnetic resonance imaging, DWI: diffusion-weighted imaging

\section{Discussion}

Non-alcoholic WE was first described by Carl Wernicke himself in 1881 in a woman with pyloric stenosis and persistent vomiting from sulphuric acid ingestion who, on autopsy, was found to have bilateral punctate haemorrhages along the wall of the third ventricle [8]. He described a clinical triad of acute encephalopathy, ophthalmoplegia/nystagmus and gait ataxia. In 1997, Caine et al. suggested that a diagnosis of WE can be made if two of the four criteria are satisfied: (1) eye signs, (2) cerebellar signs, (3) memory impairment or confusion and (4) evidence of malnutrition on physical examination or from laboratory data [9]. Confusion is the most common presenting symptom occurring in about $82 \%$ of cases, followed by oculomotor abnormalities in $29 \%$, gait ataxia in $23 \%$ and polyneuropathy in $11 \%$ [10]. Atypical clinical presentations include stupor, hypotension, vestibular dysfunction without hearing loss and beriberi heart disease that has been rarely reported with WE. While alcohol abuse remains the most common precipitating factor for WE, non-alcoholic aetiologies include starvation, hyperemesis gravidarum, IV infusion of glucose before thiamine, prolonged chemotherapy (5-fluorouracil (FU) infusion, doxyfluridine and ifosfamide), dialysis (thiamine is water soluble), anorexia nervosa, refeeding syndrome and gastrointestinal surgery. Thiamine is a water-soluble vitamin absorbed in the duodenum and stored primarily in the liver with body stores typically lasting up to 18 days [11]. The absorption of thiamine occurs in the duodenum by a carriermediated process (inhibited by alcohol via interference of intestinal ATPase) that requires magnesium as a cofactor; hence, hypomagnesaemia can mimic thiamine deficiency [11]. Thiamine plays a significant role in the Krebs cycle and pentose phosphate pathways. Thus, a deficiency in thiamine typically affects the metabolically active regions, producing vascular congestion with or without petechial haemorrhages in the acute phase and demyelinating, gliotic lesions in the chronic phase [4]. The prevalence of WE in patients with bariatric surgery is reported to be $\sim 8 \%$ [12]. Singh et al. performed a systematic analysis of WE cases post bariatric surgery and found that out of the 32 cases diagnosed at 2-18 weeks from the procedure, the majority presented with the classic triad of WE, while nearly 50\% had a normal MRI [13]. WE remains a clinical diagnosis that can be made even with normal blood thiamine levels and with MRI having a sensitivity and specificity of $53 \%$ and $93 \%$, respectively [5]. Only $16 \%$ of the patients eventually diagnosed with WE, however, presented with the typical clinical triad, while about $19 \%$ of the patients had none of the triad symptoms. Up to $80 \%$ of cases get missed during a routine clinical examination, and autopsy-based studies indicate that almost $82 \%$ of the patients with WE present with delirium [10]. While a presumptive diagnosis can be made by measuring the erythrocyte transketolase activity, it is limited by its lack of specificity and cost. To overcome this problem in diagnosis, consistent efforts have been undertaken in using neuroimaging techniques to support the clinical presentation of WE; however, treatment should not be delayed [10]. MRI lesions classically involve the medial thalami, especially along the third ventricular wall ( $80 \%$ to $85 \%$ ), periaqueductal areas ( $59 \%$ to $65 \%$ ), mammillary bodies ( $38 \%$ to $45 \%$ ), tectal plate ( $36 \%$ to $38 \%$ ) and dorsal medulla with the involvement of hypoglossal nuclei (8\%) [10]. Other less common sites are the corpus callosum, caudate nucleus, red nucleus, dentate nucleus, cerebellum, hippocampus and frontal and parietal cerebral cortices. These regions are more prone to being sensitive to thiamine deficiency. Gross haemorrhage is uncommon in acute WE, but it has been reported on CT scans [10]. Prompt administration of thiamine leads to an improvement in the ocular signs within hours to days, vestibular function and gait ataxia during the second week, and confusion subsides over days to weeks. Abnormal T2 signal disappears as 
early as two days after treatment with thiamine; in our specific case, we observed a significant radiographic resolution within a week of starting thiamine.

\section{Conclusions}

With the advancements in the neuroimaging techniques, MRI findings are useful in the early diagnosis of WE, especially with non-alcoholic cases with atypical clinical presentations. One must maintain a high index of suspicion for non-alcoholic WE, as a prompt initiation of treatment can significantly reduce long-term morbidity and mortality.

\section{Additional Information \\ Disclosures}

Human subjects: Consent was obtained by all participants in this study. Conflicts of interest: In compliance with the ICMJE uniform disclosure form, all authors declare the following: Payment/services info: All authors have declared that no financial support was received from any organization for the submitted work. Financial relationships: All authors have declared that they have no financial relationships at present or within the previous three years with any organizations that might have an interest in the submitted work. Other relationships: All authors have declared that there are no other relationships or activities that could appear to have influenced the submitted work.

\section{References}

1. Arts NJM, Walvoort SJW, Kessels RPC: Korsakoff's syndrome: a critical review . Neuropsychiatr Dis Treat. 2017, 13:2875-2890. 10.2147/NDT.S130078

2. Harper C, Fornes P, Duyckaerts C, Lecomte D, Hauw JJ: An international perspective on the prevalence of the Wernicke-Korsakoff syndrome. Metab Brain Dis. 1995, 10:17-24. 10.1007/BF01991779

3. Naidoo DP, Bramdev A, Cooper K: Autopsy prevalence of Wernicke's encephalopathy in alcohol-related disease. S Afr Med J. 1996, 86:1110-1112.

4. Malamud N, Skillicorn SA: Relationship between the Wernicke and the Korsakoff syndrome; a clinicopathologic study of seventy cases. AMA Arch Neurol Psychiatry. 1956, 76:585-596.

5. Antunez E, Estruch R, Cardenal C, Nicolas JM, Fernandez-Sola J, Urbano-Marquez A: Usefulness of CT and MR imaging in the diagnosis of acute Wernicke's encephalopathy. AJR Am J Roentgenol. 1998, 171:11311137. 10.2214/ajr.171.4.9763009

6. Law HL, Tan S, Sedi R: Wernicke's encephalopathy in a patient with nasopharyngeal carcinoma: magnetic resonance imaging findings. Malays J Med Sci. 2011, 18:71-74.

7. Zuccoli G, Santa Cruz D, Bertolini M, Rovira A, Gallucci M, Carollo C, Pipitone N: MR imaging findings in 56 patients with Wernicke encephalopathy: nonalcoholics may differ from alcoholics. AJNR Am J Neuroradiol. 2009, 30:171-176. 10.3174/ajnr.A1280

8. Thomson AD, Cook CC, Guerrini I, Sheedy D, Harper C, Marshall EJ: Wernicke's encephalopathy revisited. Translation of the case history section of the original manuscript by Carl Wernicke 'Lehrbuch der Gehirnkrankheiten fur Aerzte and Studirende' (1881) with a commentary. Alcohol Alcohol. 2008, 43:174179. 10.1093/alcalc/agm144

9. Caine D, Halliday GM, Kril JJ, Harper CG: Operational criteria for the classification of chronic alcoholics: identification of Wernicke's encephalopathy. J Neurol Neurosurg Psychiatry. 1997, 62:51-60.

10. Harper CG, Giles M, Finlay-Jones R: Clinical signs in the Wernicke-Korsakoff complex: a retrospective analysis of 131 cases diagnosed at necropsy. J Neurol Neurosurg Psychiatry. 1986, 49:341-345.

11. Osiezagha K, Ali S, Freeman C, et al.: Thiamine deficiency and delirium. Innov Clin Neurosci. 2013, 10:2632.

12. Chaves LC, Faintuch J, Kahwage S, Alencar Fde A: A cluster of polyneuropathy and Wernicke-Korsakoff syndrome in a bariatric unit. Obes Surg. 2002, 12:328-334.

13. Singh S, Kumar A: Wernicke encephalopathy after obesity surgery: a systematic review . Neurology. 2007, 68:807-811. 10.1212/01.wnl.0000256812.29648.86 